\title{
EDITORIAL
}

\section{Gestação em tempos de COVID-19: como garantir a segurança e preservar os avanços conquistados?}

Nas últimas décadas, as políticas de atenção à saúde das mulheres têm passado por grandes avanços e transformações no que se refere à melhorias na qualidade da assistência, sobretudo no ciclo gravídico puerperal.

Em destaque: criação de órgãos específicos responsáveis pela elaboração das políticas de governo; direito à presença de acompanhante de livre escolha da gestante; uso de métodos não farmacológicos para alívio da dor no trabalho de parto; estímulo ao parto normal e fisiológico; além da elaboração e instituição de diretrizes assistenciais com vistas a garantir e assegurar as melhorias instituídas, com base em evidências científicas e nas boas práticas em obstetrícia1,2.

Assim, a redução das intervenções desnecessárias, reconhecidamente prejudiciais, e as cirurgias cesarianas sem indicações clínicas são estratégias de melhoria da assistência às mulheres no processo de parto e nascimento. Tais avanços foram sendo incorporados às políticas públicas de atenção à saúde, e ganhando caráter ético, político e legal nas três esferas de governo, sendo estabelecidos como avanços e conquistas garantidas por leis e diretrizes.

Porém, com o advento da pandemia do novo Coronavírus - SARS-Cov2, causador da COVID-19, surge uma grande preocupação e desafio para todos os envolvidos neste cenário de assistência à saúde das mulheres em manterem preservados todas as conquistas e avanços, sem colocar em risco a vida da gestante e seu concepto.

Certamente a pandemia de COVID-19 trouxe muitas dificuldades no atendimento à saúde da população em geral e, principalmente, as mulheres durante a gestação. A comunidade científica segue em ritmo acelerado em uma força tarefa mundial em busca por achados que redundem em benefícios para o controle e a própria cura da doença causada pelo SARS-Cov2 ${ }^{2}$.

Os pesquisadores da área da obstetrícia têm como desafio maior reduzir a morbimortalidade de mulheres grávidas e puérperas acometidas pela COVID-19. Estudos têm apontado um aumento no número de óbitos entre gestantes. Na primeira semana do mês de agosto, o Brasil ultrapassou 200 óbitos de gestantes e puérperas causadas por COVID-19, tornado assim o país mais perigoso para grávidas no contexto da pandemia ${ }^{3}$.

As mortes maternas, além de causarem grande comoção e tristeza para os familiares e a sociedade, também são indicadores da qualidade dos serviços de saúde pública oferecida em um país. O Brasil já apresenta uma taxa de mortalidade materna considerada alta, cerca de 60 mortes de mulheres grávidas ou no pós-parto por 100 mil bebês nascidos vivos, mesmo antes da pandemia 4 .

Diante destes dados alarmantes, o Ministério da Saúde vem instituindo normas técnicas visando a proteção das gestantes e seus bebês, porém as medidas instituídas acabam interferindo nos direitos conquistados ao longo do tempo, o que deve ser considerado na elaboração de tais normas ${ }^{3,4}$.

Também no pós parto muitas mulheres podem estar com receio de amamentar seus bebês por medo de infectá-los com o novo coronavírus. Contudo, a Organização Pan-Americana da Saúde (OPAS) e Organização Mundial da Saúde (OMS) recomendam que a mãe e o bebê permaneçam juntos em alojamento conjunto durante toda a internação e pratiquem o contato pele a pele, inclusive o método canguru, especialmente logo após o nascimento e enquanto estabelecem a amamentação, mesmo se elas ou os bebês tenham suspeita ou confirmação de COVID-19, observando rigorosamente as medidas de higiene e o uso da máscara, tanto para a mãe como para o acompanhante, e a não permissão de visitas ${ }^{5}$.

Portanto a pandemia do novo coronavírus está revelando as fragilidades e desigualdades, ainda persistentes, nos serviços de saúde, sobretudo quanto à assistência às 
gestantes, não obstante os avanços e conquistas. Assim, vislumbra-se novos desafios na contínua busca pelo resgate do empoderamento e autonomia da mulher para vivenciar a gestação o parto e nascimento de seus bebês de maneira humanizada, digna, respeitosa e segura, considerando a redução dos indicadores de morbimortalidade materna.

\section{REFERÊNCIAS}

1. Ministério da Saúde (Br). Secretaria de Ciência, Tecnologia e Insumos Estratégicos. Departamento de Gestão e Incorporação de Tecnologias em Saúde. Diretrizes Nacionais de Assistência ao Parto Normal. Ministério da Saúde, Secretaria de Ciência, Tecnologia e Insumos Estratégicos, Departamento de Gestão e Incorporação de Tecnologias em Saúde. Brasília: Ministério da Saúde; 2017.

2. World Health Organization. Recommendations on intrapartum care for a positive childbirth experience. Geneva: WHO; 2018.

3. Brasil. Portaria no 2.222/GM/MS, de 25 de Agosto de 2020. Institui, em caráter excepcional e temporário, Ações Estratégicas de Apoio à Gestação, Pré-Natal e Puerpério e o incentivo financeiro federal de custeio para o enfretamento da Emergência em Saúde Pública de Importância Nacional (ESPIN) decorrente da pandemia do coronavírus.

4. Ministério da Saúde (Br). Secretaria de Atenção Primária à Saúde. Departamento de Ações Programáticas e Estratégicas. Manual de Recomendações para a Assistência à Gestante e Puérpera frente à Pandemia de Covid-19 [recurso eletrônico] / Ministério da Saúde, Secretaria de Atenção Primária à Saúde. Brasília: Ministério da Saúde; 2020.

5. Benefícios da amamentação superam riscos de infecção por COVID-19, afirmam OPAS e OMS [Internet]. [Citado em 06 set. 2020]. Disponível em: https://www.paho.org/bra/index.php?option=com_content\&view=article\&id=6267:beneficio s-da-amamentacao-superam-riscos-de-infeccao-por-covid-19-afirmam-opas-eoms\&Itemid $=820$.

Boa Leitura!

\section{Efigenia Aparecida Maciel de Freitas}

Enfermeira. Especialista em Enfermagem Obstétrica. Especialista em Saúde Pública. Mestre em Ciências da Saúde. Doutora em Enfermagem Psiquiátrica. Coordenadora do Curso de Especialização em Enfermagem Obstétrica e Professora da Faculdade de Medicina da Universidade Federal de Uberlândia (UFU). Uberlândia, MG,

Brasil.

\section{Silvana Regina Rossi Kissula Souza}

Enfermeira. Especialista em Enfermagem Obstétrica. Mestre em Engenharia de Produção. Doutora em Ciências. Coordenadora do Curso de Especialização em Enfermagem Obstétrica Rede Cegonha da Universidade Federal de Minas Gerais e da Universidade Federal do Paraná (UFPR). Professora pelo Programa de Pós Graduação em Enfermagem da UFPR, Curitiba, PR, Brasil. 